Cad.Est.Ling., Campinas, 47(1) e (2):83-92, 2005

\title{
UM CERTO RETORNO À LINGÜÍSTICA PELA VIA DA PSICANÁLISE ${ }^{1}$
}

\author{
ELIANE MARA SILVEIRA \\ (PonTIFí́cia Universidade CATÓlICA-SP \\ Grupo de Pesquisa em Aquisição da Linguagem)
}

\begin{abstract}
Buscaremos situar el paso y los impasses de Cláudia Lemos en el texto "Los procesos metafóricos y metonímicos como mecanismos de cambio", publicado en 1992 en la revista española Substractum. En ese texto, la autora vuelve a la Lingüística, y esta vuelta está marcada por los síntomas de este campo, que no le impiden una elaboración respecto al proceso de adquisición del lenguaje, sino más bien desencadenan - con la opción de la autora por el Psicoanálisis - un proceso teórico productivo. Incluso, es por la vía del Psicoanálisis que se pueden hacer visibles el paso y los impasses de ese texto y indicar alrededor de qué giran cuando se trata de la lengua: el sujeto.
\end{abstract}

\section{INTRODUÇÃO}

"Science ou pas, la linguistique compte moins comme telle qu'elle ne compte comme aventure de quelques sujets." (MILNER, 2000).

Neste trabalho procuraremos mostrar um movimento radical de retorno à Lingüística realizado por Cláudia Thereza Guimarães De Lemos², em um momento de sua produção teórica, que será analisado por nós. Trata-se do texto "Los procesos metafóricos y metonímicos como mecanismos de cambio", publicado em 1992 na revista espanhola Substractum. Julgamos esse retorno à Lingüística importante especialmente quanto às consequências que ele pode trazer à noção de interação, cara aos estudos de aquisição da linguagem, desde que reconhecida a radicalidade desse movimento. É preciso salientar que se há um retorno à Lingüística não é a qualquer lingüística. O retorno é à lingüística saussureana considerando os efeitos do reconhecimento operado por um psicanalista: Jacques Lacan.

Tal lingüística implica submetimento ao estruturalismo, o que significa dizer, segundo a nossa perspectiva, que tal retorno pressupõe a impossibilidade radical de acesso ao objeto. A partir da perspectiva estruturalista que, vale lembrar, é devedora do funcionamento da

\footnotetext{
${ }^{1}$ Uma versão mais extensa desse artigo será publicado, com o mesmo nome, no livro Aquisição, patologias e clínica de linguagem, organizado por Maria Francisca Lier-de Vitto e publicado pela EDUC/FAPESP.

${ }^{2}$ Doravante Cláudia Lemos.
} 
língua para a sua fundação e não ao contrário ${ }^{3}$, qualquer objeto é apenas efeito ou causa de estrutura. Assim, a língua enquanto objeto de estudo está interditada, na sua totalidade, ao pesquisador. Além disso, a língua não perfaz uma unidade de observação na aquisição da linguagem, já que criança/adulto não serão o foco da observação pelo que o olhar constata, mas pela estrutura que movimenta o que nessa dupla se dá como aquisição da linguagem. É o que demonstra Cláudia Lemos no referido artigo.

No entanto, a relação do sujeito com o saber é marcada por impasses, constrangimentos, ou seja, se há inconsciente e, se o saber não é disjunto dele, a elaboração teórica não é realizada sem que haja o passo e os impasses. Pretendemos delinear um e outro nesse artigo de Cláudia Lemos.

A Lingüística, em especial a área da Aquisição da Linguagem, tem sido um campo fértil para o que é da ordem do embaraço ${ }^{4}$ - constitutivo do processo de elaboração - seja elevado à condição de sintoma, conforme o trabalho de M.T.G. De LEMOS (2002) e LEITE (1994). Tal fato decorre da possibilidade do embaraço não ser colocado e quando aparece é rechaçado enquanto excrescências da teoria ou encoberto como se tratasse de um engano, motivo de vergonha. Ignorar, negar, encobrir constituem as condições suficientes para que um embaraço se transforme num sintoma.

Contudo, o texto de Cláudia Lemos(1992) mostra uma outra direção que aquela dada unicamente pelo sintoma: a elaboração. Fazemos aqui uma referência ao texto freudiano de 1914: "Recordar, repetir e elaborar" (Vol.XII, p.163) em que recordar pode ser lido como trazer à lembrança fatos que se encontram 'esquecidos', mas que se relacionam diretamente com o seu sintoma; a repetição, por sua vez, sob as condições de resistência, substitui a recordação; a elaboração, enfim, deve ser feita sobre tal resistência, de forma que, num certo instante, no auge desta, o sujeito possa se aperceber do poder dos impulsos instintuais que alimentam essas mesmas resistências.

Dessa forma, iniciaremos o trabalho apontando o texto de Cláudia Lemos(1992) como lugar de intervenção em um campo do saber que é marcado por esta tendência de elevar os impasses à categoria de sintoma, mas no qual também é possível elaboração.

\title{
2. A AQUISIÇÃO DA LINGUAGEM NA LINGÜÍSTICA
}

\begin{abstract}
“(...)sur le langage, la linguistique nous aura finalement peu appris. Peu, cependant, ne veut pas dire rien." (MILNER, 2000)
\end{abstract}

\footnotetext{
${ }^{3}$ Como testemunham todos os manuscritos saussureanos. Ou seja, foi a necessidade de poder responder por um funcionamento da língua que teve como conseqüência a formulação de uma teoria que mais tarde foi chamada de estruturalista e influenciou outras áreas de saber.

${ }^{4}$ Tomamos embaraço aqui nos dois sentidos possíveis que a língua latina legou. Aquele que a língua portuguesa permite: impedimento, obstáculo, estorvo, dificuldade, mas Também aquele muito utilizado em língua espanhola: gravidez, gestação, também possível em língua portuguesa e, ainda, menstruação utilizado popularmente em nossa língua. Dessa forma pensamos, a partir dos dois caminhos de significação possíveis dessa palavra, que há um retardamento de algo que está para nascer.
} 
Cadernos de Estudos Lingüísticos 47(1) e (2) - Jan./Dez. 2005

É sabido, conforme observa M.T.G.De Lemos(2002) que "Os estudos em aquisição da linguagem pertencem a um campo interdisciplinar que é a psicolingüística"(p.62). A autora ainda afirma que "Essa inclusão, no entanto, pode ser interrogada". No percurso do seu trabalho essa questão delineia-se em torno da relação entre os estudos da aquisição da linguagem, mais especificamente da hipótese sócio-interacionista com a Lingüística. Essa relação é colocada como essencial mas problemática e, no último parágrafo da sua tese, acrescenta:

Finalmente, quanto à questão dos instrumentos necessários para incluir de fato a alteridade na hipótese sócio-interacionista remetemos o leitor ao texto"Los processos metafóricos y metonímicos como mecanismos de cambio", de Claudia Lemos (Lemos, 1992). Este texto mostra as elaborações da autora a partir da inclusão de uma referência estruturalista em sua obra, principalmente de Saussure e Jakobson, a partir da leitura que destes foi feita por Jacques Lacan. É um trabalho em curso (ênfase nossa; p.157) ${ }^{5}$.

Essa afirmação explicita a maneira particular com que Cláudia Lemos(1992) inclui o sócio-interacionismo, ou a hipótese da alteridade, nos estudos da Aquisição da Linguagem. Os instrumentos necessários a essa inclusão, referidos por M.T.G.De Lemos, são as "duas ordens de funcionamento da língua: a paradigmática e a sintagmática", que Cláudia Lemos(1992) estendeu para "os processos metafóricos e metonímicos" os quais, no referido texto desenvolve à revelia do que aponta Milner:

"Tout le monde parle du langage en général et de la langue française en particulier comme si la linguistique n'avait pas existé. Sans excepter les linguistes eux-mêmes." (2000, p.9; Grifo nosso)

Ou seja, nesse movimento de inclusão da alteridade nos estudos de Aquisição da Linguagem Cláudia Lemos(1992) não ignora a existência da Lingüística.

Nesse processo de retorno à Lingüística, mais especificamente na seção cujo título é: "Nueva visita al estructuralismo europeo: de Saussure y Jakobson" (p.124), Cláudia Lemos nomeia dois lingüistas. O primeiro foi aquele ao qual é reputada a fundação da Lingüística e o outro, Jakobson, aquele que gozou de uma certa importância na teorização de Lacan, mais especificamente na fase considerada como aquela em que se deu a inclusão da Linguística ${ }^{6}$. Dessa forma, o tratamento que Cláudia Lemos dá às questões da aquisição da linguagem, nesse momento da sua elaboração, implica uma questão duplamente delicada. Uma delas é aquela enunciada por Milner sobre a recusa, pelos lingüistas, da Lingüística. É importante notar que a Psicolingüística, área em que se insere a aquisição da linguagem, não deixa de ser um lugar interessante para quem queira se abrigar da Lingüística já que a psicologização ali não é impedida de imperar.

${ }^{5}$ Este parágrafo pertence à tese defendida pela autora em 1994 e que deu origem ao livro com o mesmo nome publicado em 2002. Referimos este parágrafo à tese pois a edição dessa que resultou em livro não manteve tal observação que, não obstante, é importante para o nosso trabalho.

${ }^{6}$ Roudinesco atribui à chamada fase estruturalista de Lacan os textos escritos entre 1950 e 1962 nos quais "Só subsistia, como instrumento de um retorno a Freud, um cotejo de nomes: Jakobson, Benveniste, Saussure" (1994, p.311). 
Cláudia Lemos(1992) retorna à Lingüística a partir de Lacan quando já não mais se trata do campo daqueles que operam sobre a língua desconhecendo (ou negando) a Lingüística, como alerta Milner? ${ }^{7}$. Vale observar como a autora reintroduz a Lingüística nos estudos da aquisição da linguagem:

De hecho, la interpretación por parte de Lacan de estos conceptos lingüísticos equivale a una reinterpretación radical de los mismos, pues realza precisamente todo aquello que el campo de la lingüistica había rechazado. Tales reinterpretaciones muestran la posibilidad de considerar algunas de las ideas de Saussure y de Jakobson como una vía de alejamiento del empirismo por lo que respecta a los enfoques socio-interaccionistas de la adquisición del lenguaje. (op. cit.: 124).

Vê-se que este particular retorno à Lingüística implica uma outra relação com o que fica recalcado no ato inaugural da Aquisição da Linguagem, tal qual M.T.G.De Lemos(2002) assegura:

Interessa-nos concluir que a psicolingüística, ou pelo menos essa psicolingüística (...) foi uma resposta a uma questão que nunca encontrou uma possibilidade de ser colocada enquanto tal. Essa questão foi, sem dúvida, a dos efeitos produzidos sobre a noção de sujeito a partir do reconhecimento da incidência da ordem lingüística sobre os fenômenos subjetivos. (p.50, grifo nosso).

Nesse contexto, o dos estudos em Aquisição da Linguagem na Psicolingüística tal como ela surgiu, e da Lingüística com as marcas da sua fundação, o que se dá no texto de 1992 é uma invenção, ou seja, uma nova articulação com os mesmos significantes. A autora nomeia esse seu trabalho de "uma proposta alternativa ao processos reorganizacionais" e aponta o seu objetivo: encontrar uma via de afastamento do empirismo no que diz respeito aos enfoques sócio-interacionistas na aquisição da linguagem, ou, como afirmou M.T.G.De Lemos, trata-se de nomear os instrumentos necessários para incluir de fato a alteridade na hipótese sócio-interacionista.

\section{O(S) PROCESSO(S)}

"Ce point étant admis, on comprend que Lacan rapelle que ce qui importe à l'inconscient, ce n'est pas la science linguistique comme telle, mais le langage." (MILNER, 2000).

A partir da consideração das ordens sintagmáticas e paradigmáticas como as duas possibilidades de relações na linguagem, algo, na tentativa de explicar a aquisição da linguagem, parece estar definitivamente alterado. Segundo Cláudia Lemos(1992), entretanto, isso não é o suficiente e ela lançará mão dos processos metafóricos e metonímicos com o objetivo de dar um passo nas tentativas de explicar a aquisição da linguagem.

${ }^{7}$ Aqui não se trata de uma exclusão de qualquer referência à Lingüística, mas da exclusão do que lhe é próprio, de seu objeto, a língua. 
Cadernos de Estudos Lingüísticos 47(1) e (2) - Jan./Dez. 2005

Interessa-nos, portanto, a passagem destas duas ordens de relação para os dois mecanismos: metafóricos e metonímicos. Ou seja, quais são os aspectos que Cláudia Lemos privilegia nos processos metafóricos e metonímicos para que eles possam vir em suplência das relações sintagmáticas e paradigmáticas.

Voltemos, assim, ao trabalho de Cláudia Lemos no texto de 1992. Ela se propõe a entender os processos metafóricos e metonímicos a partir das figuras que os identificam e, após uma breve exposição, conclui que: "No hay duda de que aunque algo importante de naturaleza sintáctica sea iluminado por esta reinterpretación, hay mucho más que desarrollar para dar cuenta de fenómenos específicos de la sintaxis de las lenguas naturales constituidas"( p.127).

Nota-se, pelo texto, que a natureza sintática da língua consegue ser melhor explicada pelos processos metafóricos e metonímicos que pelas relações sintagmáticas e paradigmáticas, embora tais processos ainda não sejam suficientes para explicar os fenômenos específicos da sintaxe das línguas naturais adquiridas, nas suas palavras. No entanto, ela acrescenta, a seguir, que isso não impede de reconhecer as possibilidades que, com esta interpretação, se abrem para a descrição de fenômenos e a compreensão de problemas que oferecem resistência a teorias que partem, precisamente, de categorias e estruturas já constituídas.

Cláudia Lemos encerra essa passagem das duas ordens de relações para os dois processos afirmando que:

El estructuralimo como programa teórico puede, desde mi punto de vista, servir como base para responder a esas cuestiones. En primer lugar, porque permite dar cuenta del proceso por el cual el léxico es categorizado y también permite considerar la relación de solidaridad de esa categorización con la formación de estructuras. En segundo lugar, porque en la medida en que los procesos metafóricos y metonímicos responsables de esa categorización son interdependientes, no es posible suponer la adquisición ordenada de componentes: suponer por ejemplo que el léxico preceda y condicione la adquisición de la morfología y de la sintaxis (op. cit.: 128).

Este fragmento do seu texto parece não deixar claro o que é da ordem dos processos e o que é da ordem das relações, ou qual o limite entre um e outro. Quando ela afirma que o estruturalismo permite dar conta do processo pelo qual o léxico é categorizado e considera a relação de solidariedade dessa categorização com a formação de estruturas parece que as relações sintagmáticas e paradigmáticas foram propostas por ela como capazes de engendrar tais posições na língua.

Quando a autora usa a expressão "en segundo lugar", há uma diferenciação, um acréscimo, ao que já estava colocado antes e, nesse momento, ela explicita os processos metafóricos e metonímicos como interdependentes, o que lhes dá uma característica importante na hipótese da aquisição da linguagem. Não é possível que o léxico preceda e condicione a aquisição da morfologia e da sintaxe. Veremos, mais tarde, que tal característica também é atribuída, por Saussure, aos processos sintagmáticos e paradigmáticos, no Curso de Lingüística Geral ${ }^{8}$.

${ }^{8}$ Doravante CLG. 
Sendo assim, é parte do nosso trabalho situar um embaraço ${ }^{9}$ na passagem dos processos para os mecanismos. Esse embaraço se situa primeiramente do lado do leitor para o qual a compreensão falha e é necessário dar relevo ao que falha nessa falta de clareza para que se possa interrogar o movimento de uma certa área de pesquisa que não está fora da Lingüística.

Desta maneira, acreditamos que seja importante estabelecer que há pouca coisa que diferencie estes dois processos: tanto um quanto outro são interdependentes, o que não justificaria manter os processos metafóricos e metonímicos como os únicos capazes de tal relação. É verdade que os processos metonímicos oferecem uma possibilidade maior de estruturação da sintaxe do que o eixo sintagmático; no entanto, como já vimos anteriormente, a autora também não estava convencida de que este movimento explicasse o funcionamento sintático das línguas naturais.

Contudo, não é sem motivos que Cláudia Lemos procura outra forma de entendimento das estruturas da língua na criança. Ela é clara quanto às diferenças que busca para além de Saussure.

Uma diferenciação importante que se apresenta é aquele é que o objeto de Saussure é a língua enquanto sistema e não como modo de funcionamento na fala individual, ou seja, o sujeito não está contemplado no funcionamento da língua desde Saussure.

Ao propor metáfora e metonímia como os processos de mudança na aquisição da linguagem, Cláudia Lemos lançou mão de duas figuras de linguagem, cujo estudo é realizado mais especificamente no campo da estilística, por serem estas reconhecidas como recursos de estilo.

“'L'style, c'est l'homme même' disse Buffon" e nos lembrará Enkvist ao fazer um inventário do que vem a ser estilo. Ele afirma que alguns autores atribuem o estilo ao nível saussuriano de 'parole' e não de 'langue', exatamente como outros contrastam 'le langage d'un seul' com 'le langage de tous' e dessa forma a Estilística é 'la linguistique de la parole' por oposição a 'la linguistique de la langue.”(ENKVIST, 1970, p.37). Nesse aspecto destacamos Jakobson, que parece ser solidário com essa aproximação do funcionamento metafórico e metonímico com o que é da ordem da fala ou do individual:

Manipulando esses dois tipos de conexão (similaridade e contigüidade) em seus dois aspectos
(posicional e semântico) - por seleção, combinação e hierarquização - um indivíduo revela seu
estilo pessoal, seus gostos e preferencias verbais. (JAKOBSON, 1970, p.56, grifo nosso).

Observemos que Jakobson produziu algo a partir dos impasses de Saussure. Ou seja, ali onde o pai da Lingüística vacilou, o lingüista russo propôs um funcionamento que apreendesse justamente o ponto problemático da teoria saussureana: o individual. No entanto, não foi Jakobson quem pode explicitar melhor o que era o individual, excluído por Saussure e recuperado por ele.

\footnotetext{
${ }^{9}$ Gostaríamos de trazer uma referência ao termo embaraço feita por Lacan no Seminário X na lição de 14 de novembro de 1962 e que é particularmente ilustrativa do movimento em questão neste trabalho: “(...)manifestamente, o vento sopra sobre mim, se vocês percebem que embarras embaraço é exatamente o sujeito $\mathrm{S}$ revestido da barra, que a etimologia imbaricare faz, falando com propriedade, alusão mais direta à barra como tal bara e que do mesmo modo é a imagem do que se chama o vivido mais direto do embaraço." (p.8 - Documento de circulação interna do Centro de Estudos Freudianos do Recife).
} 
Cadernos de Estudos Lingüísticos 47(1) e (2) - Jan./Dez. 2005

Cláudia Lemos(1995) é bastante específica sobre esse impasse de Saussure que, a nosso ver, determinou essa passagem das relações para os processos quando ela afirma que, a partir do momento em que Saussure define a língua como um sistema que conhece somente a sua ordem própria, ele exclui da lingüística tudo que pertence à fala, ou seja à esfera individual e acrescenta:

Contudo, o que é excluído retorna como indagação sobre o espaço livre que a língua deixa para o 'próprio da fala', identificado por ele à 'liberdade de combinações', (CLG; p.144). O individual que retorna, então não é o mesmo que foi excluído enquanto instância fisiológica e psicológica determinante do lingüístico que se dá no signo como imagem acústica e como conceito. O individual que retorna é o que se dá na esfera da fala, definida agora como espaço do não previsto, onde se pode exercer a 'liberdade de combinações'. (Cláudia Lemos, 1995, p.12, grifo nosso).

A autora define o excluído por Saussure do objeto da lingüística: a irrupção na cadeia da fala do imprevisível no funcionamento da língua. Conhece-se o movimento mas não o efeito. Assim, ela se pergunta “como manter a dicotomia língua vs. fala?" e conclui apontando uma diferença entre Saussure e Jakobson a esse respeito:

Em contraste com o indivíduo saussureano, o 'locutor individual' de Jakobson está submetido às unidades estratificadas no código, mas tem no texto seu domínio de expressão. Para Saussure o indivíduo está sempre sujeito a um funcionamento da língua, já que restrição e imprevisibilidade não se distribuem de forma desigual entre fonema e palavra, sentença e texto.(Cláudia Lemos, 1995, p.15-16).

Assim, sabemos que metáfora e metonímia trazem uma questão deixada em suspenso no CLG, ou seja, como o sujeito imiscui-se na estrutura? Jakobson recoloca essa questão em seu artigo e Cláudia Lemos a desenvolve em mais de um artigo seu, em especial naquele que é objeto deste trabalho. Mas sabemos agora que Cláudia Lemos não é solidária com a estilística. Se, por um lado, reconhece o movimento de Jakobson de qualificar o individual para além da fala também na língua, por outro lado não lhe parece que tal articulação seja suficientemente forte para sustentar o seu empreendimento: apreender um movimento constitutivo (do quê?) na fala da criança.

Dessa forma, o que podemos dizer é que o que é da ordem da 'fala individual' não fica suficientemente articulado com os processos metafóricos e metonímicos, mas parece indicado pela autora. Na verdade, o que é da ordem da 'fala individual' aparece na exposição dos dados, pois, ao apontar o funcionamento de tais mecanismos na fala da criança, fica claro que a fala é o lugar de emergência do sujeito. Porém, ela não deixa de insistir na língua imbricada com a fala em especial ao analisar os dados. É neste momento que Cláudia Lemos demonstra a radicalidade da sua proposta, a fala da criança está submetida à fala do outro, este submetimento se dá por meio dos referidos processos, como ela mostra em seus dados e, no entanto, não há previsibilidade na fala da criança. Aliás, é na ruptura que se pode sustentar que houve algum desses processos.

Pensamos que a proximidade que se constata entre os processos metafóricos e metonímicos e as relações sintagmáticas e paradigmáticas podem ser a causa ou o mesmo o efeito da falta de explicitação do sujeito da linguagem implicado nas elaborações de Cláudia Lemos nesse artigo. 


\title{
4. AFÂNISE E EMERGÊNCIA DO SUJEITO
}

\author{
“(...) la nouveauté qui perdure, c'est que l'affirmation \\ immémoriale 'les hommes parlent' (=langage) a pris désormais \\ une portée radicalement nouvelle et cela, depuis qu'une \\ linguistique est possible." (MILNER, 2000)
}

Vejamos como a questão do sujeito aparece literalmente no seu texto: "Como se trata además de algo, en cuya constitución está necessariamente implicada la relación com los datos lingüísticos o, desde mi punto de vista, com el discurso del outro, esa descripción se torna todavia más problemática." (Cláudia Lemos, 1992, p.127, grifo da autora). E ao final desta seção: "La interacción com el outro se torna, en nuestra propuesta, una condición necessaria. Pienso en el outro en tanto discurso o instância de funcionamiento de la lengua constituída." (p.128). Esse outro, em itálico, parece responder pela inclinação da autora em definir a fala individual. Sabemos que o outro ocupa um lugar princeps na teorização lacaniana do sujeito que certamente orienta estas reflexões seja pela referência a este autor feita no início do artigo, seja pela condução do mesmo. No entanto, é importante notar que não houve uma importação do sujeito da Psicanálise para a Aquisição da Linguagem como forma de solucionar os impasses dessa área, como se pode concluir apressadamente em uma primeira leitura do artigo, mas um passo na elaboração teórica sobre a aquisição da linguagem que é compatível com a hipótese de Lacan de que o inconsciente se estrutura como uma linguagem.

Essa hipótese se firma quando Cláudia Lemos mostra, na unidade mínima de análise de aquisição da linguagem por parte da criança: a interação adulto/criança em situação de fala, como operam os mecanismos de mudança. Nesse momento ela é explícita: "Si la experiência com el lenguaje no supone una actividad consciente, el efecto reorganizador de oir y producir enunciados debe ser interpretado como efecto del lenguaje sobre el proprio lenguaje" (p.132). Ou seja, atividade da linguagem não é consciente (o que não é o mesmo que inconsciente) e as mudanças na aquisição da linguagem acontecem como efeito da linguagem sobre a própria linguagem sendo que, para Cláudia Lemos, como mostramos acima, os dados lingüísticos são o discurso do outro, ou seja, o outro enquanto discurso ou instância de funcionamento da língua constituída, nas suas palavras.

Para além dos indícios que temos na sua elaboração teórica é em outro lugar que o sujeito chega sem muito avisar, mas inconfundível.

A fala da criança, o corpus, não é o sujeito como se poderia pensar, mas é uma espécie de testemunho do sujeito. A criança, entre duas cadeias de fala do adulto, deixa saltar algo que, modificado, é distinto do que estava presente na fala do adulto, mas guarda nitidamente, nessa novidade, a fala do adulto. Aí onde há uma diferença sensível, entre os significantes de uma cadeia e outra, é que Cláudia Lemos situa a sua descoberta. Não é como se poderia pensar num primeiro momento, nas suas articulações teóricas, simplesmente que haja elaboração nesse artigo. É principalmente naquilo que ela pode escutar ${ }^{10}$ da fala da criança,

${ }^{10}$ Diferenciando aqui de ouvir, mas não equiparado à escuta analítica que implica uma intervenção que permita a emergência do sujeito do desejo. 
uma fala que imbricada com a língua mostra o esboço de uma passagem na língua. Ora, isso que se manifesta entre estas duas cadeias lingüísticas e apresenta uma posição na língua é o quê?

Sendo assim, toda interpretação deste texto que supõe que há aí uma teoria do sujeito como efeito do significante está devidamente ancorada no que Cláudia Lemos anuncia e os dados mostram. Entretanto, ela se detém e não chega, em nenhum momento do artigo, a falar do sujeito do inconsciente como efeito das observações e elaborações que ela realiza a partir da fala da criança.

\title{
5. CONSIDERAÇÕES FINAIS
}

\author{
"À ce registre, la linguistique continue de compter, parce que \\ ses aventuriers, par leur ratage, plus que par leur réussite, \\ ont touché quelques récifs de réel." (MILNER, 2000)
}

CARVALHO \& AVELAR(2000) se perguntam: "Poderia o infante ser estudado em sua singularidade por um investigador que se concebe como um sujeito em que não falta um controle sobre a língua?" (p.5). Ou seja, quais as condições de escuta de um linguista diante da fala da criança? Se concordamos que a Lingüística tem preferência por operar na sutura como afirma Milner em "O amor da Língua", ou seja, o sintoma não lhe é indesejável, é possível pensar que a escuta desde este campo não seja algo assim tão fácil, já que o saber sobre a língua pode encobrir o saber da língua.

É nesse ponto que os dados trazidos por Cláudia Lemos(1992) qualificam aquilo que pelas explicações teóricas não está explícito: o sujeito. O que chamamos de impasse está intimamente ligado ao desejo do investigador e assim não aparece a não ser pelas suas artimanhas. Desejo não é sinônimo de vontade, de intencionalidade que, segundo o trabalho já citado:

(...)a suspensão da intencionalidade da criança tem como contrapartida a suspensão da intencionalidade do investigador, o que traria como consequência a submissão também deste último sujeito ao funcionamento da língua, no momento mesmo da investigação." (CARVALHO \& AVELAR, 2000, p.5).

Assim, a língua para o lingüista é mais do que um objeto: é uma experiência da qual depende o resultado do seu trabalho. Quanto à psicanálise M.T.G. De Lemos(2002) afirmou que é uma práxis e não uma teoria. E quanto à Lingüística, há ainda a possibilidade de ela vir a ser uma práxis? É ainda Carvalho, em outro trabalho, quem afirma “(...) Diante do espelho [enquanto função constituinte], dois caminhos poderiam ser seguidos pelo investigador. Um deles consistiria em apagar o impasse, na tentativa de restaurar a homogeneidade ameaçada." (CARVALHO, 2000, p.4). Ainda haveria outro caminho e é nesse que encontramos Cláudia Lemos:

\footnotetext{
"Um outro caminho consistiria em se confrontar com o impasse buscando explicitá-lo. Essa busca significaria uma tentativa de não apagar a diferença, ou melhor, uma tentativa de atender ao compromisso com a singularidade da fala da criança." (Cláudia Lemos, 1995).
} 
Sendo assim, o sujeito que aparece nesse artigo não é mais apenas um, mas tem apenas um estatuto. Nós temos aqui o investigador no seu estatuto de sujeito nos impasses teóricos e a criança no seu estatuto possível de sujeito pela qualificação dos dados. O estatuto desse sujeito, nós podemos adiantar, é apenas um: o sujeito dividido.

\section{REFERÊNCIAS BIBLIOGRÁFICAS}

CARVALHO, G. \& AVELAR, T. (2000). O erro e o diálogo em aquisição da linguagem, mimeo.

CARVALHO, G. (200). Children's errors and problematic status of recognition of comunicative intentions, mimeo.

FREUD, S. (1988). Obras Completas. Vol.XII. Editora Imago. Rio de Janeiro.

ENKVIST, N. et al. (1970). Lingüística e Estilo. São Paulo: ed. Cultrix.

JAKOBSON, R. (1970). Lingüística e Comunicação. São Paulo: ed. Cultrix.

LACAN, J. Seminário X. mimeo. - Documento de circulação interna do Centro de Estudos Freudianos do Recife.

LEITE, N. V. de A. (1994). Psicanálise e Análise do Discurso. Rio de Janeiro: Editora Campo Matêmico.

De LEMOS, C. T. G. (1992). "Los Processos Metafóricos e Metonímicos como mecanismos de cambio". In: Substratum, v. 1; $\mathrm{n}^{\circ} 1$; pp. 121-135. Barcelona.

(1995). "Língua e discurso na teorização sobre aquisição da linguagem". In: Letras de Hoje, v. 30, $\mathrm{n}^{\circ}$ 4, pp. 9-28; Porto Alegre, dezembro.

De LEMOS, M.T.G. (2002). A língua que me falta. Campinas: Mercado de Letras; São Paulo: FAPESP.

MILNER, J.C. (2000). De la linguistique à la linguisterie ps.7-25. In “Lacan, L'écrit, l'image”; Sous la direction de L'Ecole de la cause freudienne; Flammarion.

MILNER, J.C. (1987). O Amor da Língua. Porto Alegre: Artes Médicas.

ROUDINESCO, E. (1994). Jacques Lacan: Esboço de uma vida, história de um sistema de pensamento. São Paulo: Companhia das Letras.

SAUSSURE, F. (1973). Curso de Lingüística Geral. Org.por Charles Bally e Albert Sechehaye com a colaboração de Albert Riediliger. $5^{a}$ ed. São Paulo: ed. Cultrix. 